\title{
Child protective service referrals involving exposure to domestic violence: Prevalence, associated maltreatment types, and likelihood of formal case openings
}

\author{
Bryan G. Victor, Ph.D.* \\ Indiana University \\ Colleen Henry, Ph.D. \\ Hunter College, City University of New York \\ Terri Ticknor Gilbert, MSW \\ University of Michigan - Ann Arbor \\ Joseph P. Ryan, Ph.D. \\ University of Michigan - Ann Arbor \\ Brian E. Perron, Ph.D. \\ University of Michigan - Ann Arbor
}

* Corresponding author: Bryan G. Victor, Ph.D., Associate Professor, School of Social Work, Indiana University, 902 West New York Street, Indianapolis, IN 46202. E-mail:

bgvictor@iu.edu

Paper to appear in Child Maltreatment.

This is the author's manuscript of the article published in final edited form as:

Victor, B. G., Henry, C., Gilbert, T. T., Ryan, J. P., \& Perron, B. E. (2019). Child Protective Service Referrals Involving Exposure to Domestic Violence: Prevalence, Associated Maltreatment Types, and Likelihood of Formal Case Openings. Child Maltreatment, 24(3), 299-309. https://doi.org/10.1177/1077559519843605 


\begin{abstract}
Childhood exposure to domestic violence (CEDV) is widely understood as potentially harmful to children. Accordingly, many child welfare systems in the United States construe CEDV as maltreatment when the exposure results in harm or threatened harm to the child. The purpose of the current study was to investigate substantiated child welfare referrals directly related to CEDV to better understand the prevalence and patterns of CEDV-related maltreatment, and how child welfare workers respond under the "harm or threatened harm" standard. Data were drawn from 23,704 substantiated referrals between 2009 and 2013 in a large Midwestern child welfare system. Approximately $20 \%$ of substantiated referrals were CEDV-related. A plurality of CEDV-related referrals included both a male caregiver and female caregiver who were cosubstantiated for maltreatment. The most common maltreatment types substantiated for these referrals were neglect-based rather than abuse-based, and just under a quarter (23\%) of CEDVrelated referrals were formally opened for services. Referrals involving co-occurring substance abuse were most likely to be opened for services based on predicted probabilities derived from multilevel modeling. Implications for policy and practice are considered.
\end{abstract}

Keywords: intimate partner violence; substantiation; child protective services; child welfare policy; witnessing domestic violence 


\section{Introduction}

Childhood exposure to domestic violence (CEDV) is a widespread social problem. Researchers estimate that $16-25 \%$ of American youth are exposed to domestic violence during childhood (Finkelhor, Turner, Shattuck, \& Hamby, 2015; McDonald, Jouriles, Ramisetty-Mikler, Caetano, \& Green, 2006). Exposure to this type of violence is commonly understood to be potentially harmful to children (Cater, Miller, Howell, \& Graham-Bermann, 2015; Holt,

Buckley, \& Whelan, 2008). For instance, children exposed to domestic violence are more likely than their non-exposed peers to develop externalizing problems such as physical aggression and internalizing problems such as anxiety or depression (Holt et al., 2008; Kernic et al., 2003). Such exposure may take the form of visually witnessing episodes of physical or psychological abuse, hearing such episodes, or later viewing the impact of abuse (e.g., seeing bruises or damaged property) (Holden, 2003; Naughton, O’Donnell, \& Muldoon, 2017).

Less agreement exists, however, concerning whether the potential harm from CEDV merits its codification as an actionable form of child maltreatment in law or formal child welfare policy. Some child welfare agencies have determined that intervention is warranted following any exposure to domestic violence in light of the evidence that CEDV can harm child development. Yet a number of scholars have advocated for a more nuanced approach given the practical realities of intervening on such a large scale, the resilience that many children exhibit in response to CEDV, and the potential for unnecessary infringements on parental rights, particularly for parents who are survivors of domestic violence (Edleson, 2004; Henry, 2017; Kantor \& Little, 2003; Nixon, Tutty, Weaver-Dunlop, \& Walsh, 2007).

Reflective of this divide, formal child welfare policy varies by jurisdiction with respect to CEDV, particularly in the United States (Child Welfare Information Gateway, 2016; Henry, 
2017; Nixon et al., 2007). This variation is manifested in differing state definitions for what constitutes CEDV and the conditions under which child welfare agencies are directed to intervene. For instance, some states define CEDV as an act of domestic violence committed in the physical presence of a child, some include hearing such an act, and others do not formally define the concept (Child Welfare Information Gateway, 2016). In terms of how to respond, a number of states have statutes that classify CEDV in and of itself as a type of child maltreatment, and instruct child protective services (CPS) workers to determine whether formal intervention is merited in these circumstances (see Utah Civil Code §78A-6-105; Child Welfare Information Gateway, 2016). Other states have experimented with the classification of CEDV in and of itself as maltreatment, but later changed course. For example, the Minnesota state legislature passed a law in 1999 making CEDV an actionable form of neglect given the evidence that exposure could adversely affect child development (Edleson, Gassman-Pines, \& Hill, 2006). Shortly after passage, however, the number of maltreatment cases in the state increased dramatically, overwhelming the child welfare system and causing legislators to amend the law.

At the agency level, child protective services in New York City also implemented a policy of CEDV in and of itself as an actionable form of child maltreatment. The official agency policy was to consider parental "engagement" in domestic violence in any form - either as the perpetrator or as the victim - to be an act of neglect meriting the child's potential removal from the home (Dunlop, 2004). Believing the removal of their children based solely on their domestic violence victimization to be a violation of their Constitutional rights, a group of New York City mothers filed a federal suit-Nicholson v. Scoppetta. After a series of federal and state supreme court hearings, a settlement agreement was signed with the City in 2004 banning the practice (Dunlop, 2004). Following the agreement, the child protective services agency was required to 
demonstrate that a child endured harm as a direct result of CEDV, and that no other action could be taken other than removal to ensure the safety of the child (Moles, 2008). The circumstances of the Nicholson case highlight the complexity of substantiating maltreatment related to CEDV, and the risk of classifying survivors of domestic violence as perpetrators of child maltreatment on the basis of their victimization.

Mindful of this complexity, a number of state-level child welfare agencies now have policies in place that reflect the approach in the Nicholson decision of excluding CEDV in and of itself as an actionable form of child maltreatment (see for example: North Carolina Division of Social Services, 2016; Vermont Department for Children and Families, 2017). That is, CEDV itself does not inherently constitute maltreatment. Instead, exposure to domestic violence must be shown to have caused harm or the threat of harm - as defined by the respective agency - to be classified as child abuse or neglect.

Despite the existence of state-level policies requiring that CEDV result in direct harm or threatened harm to constitute maltreatment, to date, little research has examined the prevalence or patterns of CEDV-related maltreatment in jurisdictions with these policies. Moreover, because CEDV is not consistently categorized as a distinct type of child maltreatment (or reported in national child maltreatment statistics) in the United States, little is known about the prevalence or the types of CEDV-related abuse and neglect that bring children into contact with the child welfare system (Henry, 2017; U.S. Department of Health \& Human Services, Administration for Children and Families, 2016). Most research on domestic violence in child welfare populations in the United States has focused on the co-occurrence of CEDV and child maltreatment or the association of CEDV and child welfare outcomes, rather than the harm or threat of harm 
perceived by CPS workers to result directly from CEDV (English, Edleson, \& Herrick, 2005; Kohl, Edleson, English, \& Barth, 2005; Ogbonnaya \& Pohle, 2013).

A few county-level studies have been conducted in which the researchers investigated how CEDV is treated as a type of abuse or neglect and/or understood to be the cause of substantiated maltreatment. Coohey (2007) examined a sample of 1,248 substantiated maltreatment referrals between 1997 and 2002 from an urban Midwestern county that required harm or the threat of harm to substantiate CEDV as abuse and/or neglect. While CEDV was identified in $35 \%$ of referrals (i.e. domestic violence as familial risk factor), only 31 cases (2.5\%) involved substantiated maltreatment linked to CEDV. The maltreatment in these cases was classified as supervisory neglect, primarily due to threatened harm or perceived emotional harm. Children were removed from the home in $18.5 \%$ of substantiated CEDV-referrals.

In a similar study, Henry (2018) examined a random sample of 295 child maltreatment referrals received and investigated by a large California county child welfare agency between 2011 and 2012. While the state did not define CEDV as a type of maltreatment in statute, Henry found that alleged CEDV did trigger child welfare investigations. In her review of workers' investigative narratives, she found that at time of referral, child protection workers used statutory maltreatment types, primarily the type emotional abuse, to construe alleged CEDV as a type of abuse or neglect. Just under $15 \%$ of substantiated referrals in the sample involved maltreatment resulting from CEDV alone, and of these approximately $78 \%$ were formally opened for either inor out-of-home services.

\section{Current Study}

Child welfare agency adoption of the "harm or threatened harm" standard articulated in Nicholson represents an important policy shift designed to promote child safety and well-being 
while also protecting survivors of domestic violence from undue punishment. Yet the limited research in this area constrains our ability to assess how that policy shift plays out in practice. Indeed, the broad nature of the "harm or threatened harm" standard requires CPS workers to act as street-level bureaucrats (Lipsky, 1980). This means CPS workers are entrusted with making front line decisions as to whether (threatened) harm from CEDV is present, the form that such (threatened) harm takes, who is responsible, and whether the severity of the (threatened) harm justifies formal intervention. As a result, more research is needed for child welfare administrators and policy makers to evaluate whether application of the "harm or threatened harm" standard by CPS workers conforms to the policy's underlying intent.

We therefore build on the work of Coohey (2007) and Henry (2018) by using populationlevel administrative data from an entire state. Compared to studies with small samples, this approach enhances the precision of estimates and offers the opportunity to use a broader range of analytic procedures to both address research questions and provide actionable insights for system improvement. Specifically, through review of statewide administrative child welfare data, we seek to (1) estimate the prevalence of substantiated maltreatment referrals that involve CEDVrelated harm or threatened harm; (2) examine the types of substantiated maltreatment that CPS workers associate with CEDV-related harm or threatened harm for each referral and who they deem responsible; and (3) determine the predicted probability that a CPS worker will open a substantiated CEDV-related referral for ongoing child welfare services.

\section{Methods}

\section{Data}

For this study, we drew from a population level dataset of child welfare records secured through an official data-sharing agreement between a large state-level child welfare agency 
located in the Midwestern United States and [blinded for review]. These records were originally collected for internal use by the child welfare agency and contain detailed information related to all maltreatment referrals received by the agency and sent out for investigation. Variables in the records include the alleged maltreatment types, demographics (age, race, and gender) of adults and children named in the referral, the caseworker assigned to the investigation, the caseworker's decision whether to substantiate each form of alleged maltreatment, and, if substantiated, whether the referral was formally opened for ongoing child welfare services.

Records were extracted from the state's automated child welfare information system for all first time maltreatment referrals that were substantiated between 2009 and $2013(\mathrm{~N}=23,704)$. Referrals in the observation period that involved re-referrals for either alleged perpetrators or alleged victims (hereafter children) were excluded. That is, each included referral represents the first time that any perpetrator or child was named in a CPS investigation. This exclusion was implemented given our interest in how the "harm or threatened harm" standard for CEDV is applied by CPS workers independent of other factors that may influence substantiation decisions and risk assessments such as repeated CPS involvement or failure to comply with previous CPS directives.

A total of 30,188 unique perpetrators and 33,381 unique children were involved in the included referrals. Among perpetrators, $59.7 \%$ were women; a majority (70.8\%) identified as White, $24.0 \%$ identified as Black, $3.9 \%$ as multi-racial, $0.9 \%$ as Asian or Pacific Islander, and $0.4 \%$ as American Indian. Available data did not allow for Hispanic/non-Hispanic distinctions. Children were equally divided between boys (50.0\%) and girls (50.0\%) with a majority (62.2\%) identified as White, $23.1 \%$ as Black, $6.8 \%$ as Latino, $6.7 \%$ as multi-racial, $0.8 \%$ as Asian or Pacific Islander, and $0.4 \%$ as American Indian. 


\section{Policy-Practice Context}

In the state selected for study, domestic violence was defined for CPS workers in statelevel agency guidelines as a pattern of coercive control in which one intimate partner repeatedly engages in physical, psychological, sexual, and/or economic abuse against another. CEDV itself was not defined as a type of maltreatment in law, and the substantiation of referrals that alleged CEDV alone was prohibited per state-level agency guidelines. Instead, for an allegation of CEDV to be substantiated as maltreatment, the state-level agency required that alleged CEDV be co-substantiated with another allegation type reflective of the harm or threatened harm resulting from CEDV (Figure 1). For example, if a CPS worker found a preponderance of evidence that an individual had perpetrated domestic violence and this domestic violence resulted in the physical neglect of a child, then both the allegation of CEDV and physical neglect could be substantiated. If, however, the CPS worker found there was insufficient evidence of physical abuse (or any other type of maltreatment) towards the child, neither allegation could be substantiated. CEDV had to result in direct harm or the threat of harm to constitute abuse or neglect (Figure 1).

\section{INSERT FIGURE ONE ABOUT HERE}

\section{Variables}

CEDV-related referral. Referrals were classified into one of two categories $(C E D V$ related or not $C E D V$-related) based on whether they included a substantiated allegation of CEDV.

Maltreatment types. Dummy variables (yes, no) were used to indicate whether each of the following maltreatment types was substantiated in a given referral investigation: physical abuse, sexual abuse, physical neglect, failure to protect, improper supervision, threatened harm, substance abuse, and other. Physical abuse is defined as intentional or planned behavior by a 
parent that results in physical injury to the child. Sexual abuse constitutes an adult engaging or attempting to engage in sexual contact or sexual penetration of a child. Physical neglect consists of the failure to provide a child with the requisite food, clothing, or shelter needed to survive. Failure to protect is defined as knowingly permitting someone else to abuse and/or neglect a child without making appropriate efforts to intervene or keep the child safe. Improper supervision is indicated when a parent either places their child into, or fails to remove their child from, an age-inappropriate situation that results in harm or threatened harm to the child.

Threatened harm is defined as the presence of a child in a situation where harm is likely to occur based on either current circumstance (e.g., child left home alone) or past history of a parent that is unresolved (e.g., record of a crime against a child). Substance abuse is similar to CEDV in that use of illicit or controlled substances, as well as misuse of alcohol, does not inherently constitute abuse and/or neglect per agency guidelines. Instead, for substance abuse to be substantiated, the agency required that all substantiated allegations of substance abuse be co-substantiated with another allegation type of maltreatment. Like CEDV, substance abuse had to result in direct harm or the threat of harm to constitute maltreatment. Other is a catch-all category for rarely substantiated allegations such as medical abuse and intra-familial sibling violence.

Case opening. At disposition, the CPS worker determined if, based on level of risk, the substantiated referral should be closed or promoted to case status and opened for services. If the CPS worker determined that the child or children were at high risk of subsequent maltreatment then a case was opened, and the family was either mandated to receive court ordered in-home services or the child was placed into foster care. If the CPS worker determined that the child was at no or low risk the referral would be closed. A dummy variable (yes/no) was used to indicate whether a substantiated referral was formally promoted to cases status and opened for services. 
Demographic and case characteristics. Demographic variables in this study included the age and gender of the perpetrator(s), and the age, gender and race of the child(ren) at time of referral. Given that variables were assigned at the referral-level and that multiple perpetrators and/or children could be included in a single referral, age values were recorded as the age of the youngest perpetrator and youngest child involved in the referral. Case characteristics included count variables for the number of perpetrators and the number of children involved in each referral. The average number of substantiated maltreatment types, excluding CEDV, was also determined for each referral.

Assigned child protective services worker. Prior research has indicated that child welfare-decision making can vary based on which CPS worker is assigned to the case (Lee, Sobeck, Djelaj \& Agius, 2013; Victor, Grogan-Kaylor, Ryan, Perron, \& Gilbert, 2018). The administrative records used in this study included a unique identifier indicating the CPS worker assigned to each referral. The assigned worker was responsible for determining the level of risk and then deciding whether to formally open the referral for services. In rare instances a team of CPS workers made the case opening decision at disposition $(2.2 \%$ of referrals in the current sample). Identifiers were therefore produced for either the individual CPS worker or the team of workers assigned to each referral at time of disposition. These identifiers then permitted the data to be nested within the assigned CPS caseworker during multilevel modeling to account for potential variation across workers in the decision to formally open a case for services.

Child protective services county office. After referrals are screened in for investigation, the central intake worker sends them to the CPS county office located in the county where the alleged maltreatment occurred. CPS county office was included in this study so that potential unobserved differences in organizational culture and geographic location could be accounted for 
in multilevel modeling. Prior studies have noted the importance of controlling for such differences within child welfare research (Dettlaff et al., 2011; Williams \& Glisson, 2014).

\section{Analysis}

Univariate statistics and bivariate tests of association were first used to describe the sample and draw comparisons between referrals involving CEDV-related maltreatment and those referrals in which the substantiated maltreatment was unrelated to CEDV. We then limited the sample to substantiated CEDV-related referrals to draw comparisons by whether a case was formally opened, again using univariate statistics and bivariate tests of association. Effect sizes were calculated for all bivariate analyses and evaluated using Cohen's (1988) heuristics $(0.10=$ small effect, $0.30=$ medium effect, $0.50=$ large effect).

To determine the predicted probability of a formal case opening for the most prevalent patterns of CEDV-related maltreatment, we first derived adjusted odds ratios from a multilevel logistic regression model that regressed case opening decisions on maltreatment types. Three levels were included: CPS county office, assigned CPS worker, and substantiated referral. The model tested for an association between specific maltreatment types (e.g., physical abuse, failure to protect) and the decision to formally open a case while also controlling for child and perpetrator demographics. Because multiple referrals could be investigated by the same CPS worker operating out of a county-level office with other CPS workers, not all post-substantiation outcomes were independent of one another in terms of the decision to formally open a case for services. For this reason, we used a multilevel model to account for possible correlations across decisions made by the same CPS worker, or within the same CPS county office (Rabe-Hesketh \& Skrondal, 2012; Raudenbush \& Bryk, 2002). Intraclass correlation coefficients were calculated in order to estimate the amount of variance in case opening decisions attributable to 
unobserved differences between CPS workers and CPS county offices. Predicted probabilities of a formal case opening were then determined for the 15 most prevalent patterns of CEDV-related maltreatment using the posterior probability distribution of the multilevel model.

Data were missing at a rate of $1.6 \%$ for child(ren)'s race and less than $.01 \%$ for six study variables: child(ren)'s age and gender, perpetrator(s)' age and gender, assigned CPS worker, and CPS county office. Based on the very low incidence of missing data we did not make any corrections for missing values prior to multivariate analysis. All data cleaning as well as univariate and bivariate analysis was conducted using the statistical programming language, $\mathrm{R}(\mathrm{R}$ Core Team, 2017). Multilevel modeling and derivation of predicted probabilities were run using Stata 14.2 (StataCorp, 2015).

\section{Results}

\section{Prevalence and Associated Maltreatment Types}

Summary statistics for all substantiated referrals (hereafter referrals) included in the sample are presented in Table 1. Within the sample, CEDV-related maltreatment was identified in approximately $19 \%$ of referrals (Table 1). Bivariate analysis comparing CEDV-related referrals to those not involving CEDV indicated that CEDV-related referrals involved more perpetrators (Cohen's $d(d)=.50)$ and more children $(d=.39)$ on average than referrals that were not CEDV-related. Analysis also found that the mean age of the youngest perpetrator $(d=.29)$ and youngest child $(d=.47)$ were lower in referrals that were CEDV-related. In terms of gender, referrals involving male perpetrators were significantly more likely to be CEDV-related $(V=.28)$ as were those involving both boys and girls $(V=.13)$. Four maltreatment types met the threshold for a small effect size. Failure to protect (Cramer's $V(V)=.12)$ and threatened harm $(V=.22)$ were significantly more likely to be substantiated in CEDV-related referrals, while physical 
abuse $(V=.14)$ and sexual abuse $(V=.10)$ were significant less likely to be substantiated when referrals were CEDV-related.

INSERT TABLE 1 ABOUT HERE

\section{Likelihood of Formal Case Openings}

Univariate and bivariate analyses. After restricting the sample to CEDV-related referrals $(n=4,432)$, we then ran a series of bivariate analyses to draw comparisons between referrals that were formally promoted to case status and opened for services $(23.8 \%)$ and those that were closed following substantiation (76.2\%) (Table 2). On average, referrals opened for services were more likely to have a greater number of perpetrators $(d=.17)$ as well as a greater number of children $(d=.31)$. Referrals involving CEDV-related maltreatment that were formally opened for services also included a higher number of substantiated maltreatment types $(d=.85)$. Although all maltreatment types were more prevalent among referrals that were formally opened for services, only four types met the effect size threshold at the bivariate level: physical neglect $(V=.10)$, sexual abuse $(\Phi=.11)$, substance abuse $(V=.23)$ and threatened harm $(V=$

.11). Because nearly all referrals involving substantiated sexual abuse were formally opened for services, this variable was excluded from subsequent multivariate analysis.

\section{INSERT TABLE 2 ABOUT HERE}

Multilevel modeling. The adjusted odds ratios (AOR) and corresponding confidence intervals (CI) from a multilevel logistic regression predicting the decision to formally open a case involving CEDV-related maltreatment are presented in Table 3. After accounting for the nesting of case opening decisions within assigned CPS workers and CPS county offices, and controlling for demographics (e.g., mean age of the children) and case characteristics (e.g., mean 
number of perpetrators), all maltreatment types were significantly associated with an increased likelihood that a referral would formally be opened for services.

We also calculated intraclass correlation coefficients (ICC) from the model to estimate the share of variance among decisions to open a case that could be attributed to unobserved differences at the various levels of the model. The ICC for CPS workers indicates that approximately $26 \%$ of the variance in decisions to open a case can be explained by unobserved differences between CPS workers. Just over $12 \%$ of the variance was explained by unobserved differences between CPS county offices in the State.

INSERT TABLE 3 ABOUT HERE

Predicted probabilities. To facilitate interpretation of the AORs from the multilevel model and to better understand the likelihood of a formal case opening among the most common patterns of CEDV-related maltreatment, a set of predicted probabilities were derived from the posterior probability distribution of the multilevel logistic regression model (Figure 2). While a total of 99 different patterns of CEDV-related maltreatment were observed in the sample, we have presented the 15 most prevalent patterns for the sake of parsimony. Examination of the 15 most prevalent patterns revealed that all but one involved neglect (e.g., physical neglect, failure to protect, improper supervision, threatened harm). However, the highest probability of a formal case opening was observed for CEDV-related referrals that involved substance abuse or physical abuse. The probability of formal case opening for CEDV-related referrals that involved substance abuse ranged from $31.3 \%$ to $52.1 \%$. The probability of a formal case opening for CEDV-related referrals that involved physical abuse ranged from $18.6 \%$ to $34.9 \%$. The lowest 
probability of a formal case opening was observed for CEDV-related referrals that only involved neglect $(10.9 \%-29.4 \%)$.

INSERT FIGURE 2 ABOUT HERE

\section{Discussion}

The focus of this study was to assess child welfare practice related to CEDV in a statelevel child welfare agency that uses a "harm or threatened harm" standard to substantiate CEDV as maltreatment. The purpose of such a standard is to balance the potential deleterious impact of CEDV on child development with the risk of unduly punishing survivors of domestic violence in these referrals by substantiating them for child abuse or neglect. Accordingly, we examined the prevalence, case characteristics, and service response for substantiated CEDV-related referrals in order to evaluate how the use of a "harm or threatened harm" standard plays out in practice. Five noteworthy findings emerged from our analysis that increase our understanding of child welfare practice and can be used to inform future child welfare policy and research.

First, CEDV-related referrals were relatively common within the agency. Approximately $20 \%$ of substantiated referrals were CEDV-related. While prior studies have found high rates of co-occurrence (i.e., the co-occurrence of CEDV and maltreatment) among child welfare populations in the United States (Edleson, 1999; English et al., 2005), findings from our study suggest that referrals involving harm or threatened harm directly attributable to CEDV represent a significant share of substantiated referrals and agency workload. The prevalence of CEDVrelated referrals observed here was considerable greater than the $2.5 \%$ reported by Coohey (2007), and closer to the $15 \%$ reported by Henry (2018).

Second, while substantiated CEDV-related referrals overwhelming involved male perpetrators of maltreatment, a plurality of these referrals named both a male and a female 
caregiver as perpetrators of maltreatment. Substantiating both caregivers for maltreatment in CEDV-related referrals is potentially problematic in an agency that defines domestic violence through a lens of coercive control in which one partner is determined to be the perpetrator of violence and the other to be the survivor. More specifically, our findings suggest that survivors of domestic violence continue to be substantiated for maltreatment under the "harm or threatened harm" standard. Future research is needed to determine the particular circumstances under which both caregivers are substantiated in CEDV-related referrals, and whether those substantiation decisions comport with the intent of the "harm or threatened harm" standard, particularly since undue sanction of survivors has been shown to deter help-seeking (Douglas \& Walsh, 2010).

Third, CPS workers most often classified the (threatened) harm resulting from CEDV as neglect-related maltreatment (e.g., physical neglect, failure to protect, improper supervision, threatened harm) rather than abuse-related maltreatment (e.g., physical abuse). This finding is aligned with Coohey's (2007) study which found that CPS workers substantiated CEDV-related maltreatment as a form supervisory neglect. However, Henry (2018) found that CEDV-related harm or threatened harm was most frequently classified as a type of emotional abuse. Combined, these findings suggest that similar phenomena (e.g., parental acts and omissions) are captured within different categories of maltreatment across different jurisdictions, making comparison of maltreatment types and practices across states and counties difficult.

Fourth, CPS workers opened CEDV-referrals for in- or out-of-home services somewhat infrequently, doing so less than a quarter of the time. This finding suggests CPS workers tend to perceive CEDV-related harm or threatened harm as low risk for children's safety and usually do not open CEDV-related referrals for services. However, results of the multilevel model indicated considerable variability in this decision to formally promote CEDV-related referrals to 
case status. The variability across caseworkers in the decision to open a case for services suggests that CPS workers do not uniformly assess risk and safety factors in relation to CEDV, or they may lend different weight to these factors.

Fifth, while most CEDV-related referrals were not promoted to cases status, CEDVrelated referrals that were co-substantiated with substance abuse had the highest predicted probability of case opening (32.2\%-51.9\%) (Figure 2). This suggests that multimorbidity with respect to parents' psychosocial service needs are perceived to increase the risk of harm to children and increase the likelihood of formal case opening and court mandated services. Moreover, this finding points to the need for both preventative community-based and ongoing child welfare services that target both domestic violence and substance abuse. Future research might also consider examining the temporal ordering of service delivery to assess whether cooccurring psychosocial problems might best be addressed sequentially or concurrently.

\section{Limitations}

The contributions of this study need to be considered alongside its limitations. Findings drawn from the particular policy-practice context of one Midwestern state agency may not be readily generalizable to other child welfare agencies in the United States. Relatedly, patterns of substantiated maltreatment in CEDV-related referrals may also differ by state based on the set of maltreatment types available to workers in a particular jurisdiction. Our analysis was also limited by the nature and structure of the administrative data used for this study. For instance, substantiated allegations of domestic violence did not allow for a determination of whether an individual was perceived to be a perpetrator or survivor of domestic violence. We were therefore unable to estimate the precise rate at which survivors of domestic violence were substantiated for maltreatment related to CEDV. Additionally, while administrative data systematically capture 
the types of maltreatment children experience (i.e., substantiated abuse and neglect), they are limited in their ability to capture the specific parental acts and omissions that bring families to the attention of child welfare agencies or that lead to child maltreatment. As a result, we were unable to identify the particular contexts and circumstances under which CPS workers perceived CEDV as leading to harm or threatened harm for children.

\section{Implications}

Results from our study indicate that CEDV is a leading contributor to child welfare involvement for children and families. The prevalence of CEDV-related referrals, the rate at which both caregivers were substantiated for maltreatment, and the desire to avoid punishing survivors of domestic violence points to an ongoing need for effective cross-systems collaboration between child welfare agencies and domestic violence service organizations. Such collaborations may be particularly useful during investigations when CPS workers could benefit from the expertise of domestic violence specialists in evaluating for CEDV-related harm or threatened harm, and understanding the domestic violence dynamics present in the case. Domestic violence specialists could also assist in identifying ways in which survivors of domestic violence may have actively worked to protect their children given that identification of these protective acts may influence attribution of responsibility for maltreatment in these referrals.

Child welfare agencies may also consider revisions to their internal risk assessment practices given the high variability in caseworker decisions to formally open a referral for services demonstrated in this study. In recent decades, child welfare agencies have adopted standardized assessment tools to improve the reliability of frontline decision making and estimation of risk for future maltreatment (Cuccaro-Alamin, Foust, Vaithianathan, \& Putnam- 
Hornstein, 2017). While many of these tools include CEDV as a risk factor for child maltreatment, more sensitive tools appear needed to standardize CPS workers' assessment of the different types of risk CEDV can pose (Edleson, Shin, \& Johnson Armendariz, 2008; Latzman, Vivolo-Kantorb, \& Clinton-Sherroda, 2017). Development of specific tools for assessing CEDVrelated risk presents another opportunity for collaboration between child welfare agencies and domestic violence service organizations. The complexities presented by CEDV will require that both sets of expertise are leveraged in order to achieve the balance between ensuring the healthy development of children and avoiding undue punishment of survivors.

\section{References}

Administration for Children and Families. (2016). Comprehensive Child Welfare Information System. Final rule. Federal Register, 81, 35449-35482.

Cater, Å. K., Miller, L. E., Howell, K. H., \& Graham-Bermann, S. A. (2015). Childhood exposure to intimate partner violence and adult mental health problems: Relationships with gender and age of exposure. Journal of Family Violence, 30, 875-886.

Child Welfare Information Gateway. (2016). State statutes search: Child witness to domestic violence. Washington, DC: U.S. Department of Health and Human Services, Children's Bureau. Retrieved from https://www.childwelfare.gov/topics/systemwide/lawspolicies/state/?CWIGFunctionsaction=statestatutes:main.getResults

Coohey, C. (2007). What criteria do child protective services investigators use to substantiate exposure to domestic violence? Child Welfare, 86, 93-122.

Cuccaro-Alamin, S., Foust, R., Vaithianathan, R., \& Putnam-Hornstein, E. (2017). Risk assessment and decision making in child protective services: Predictive risk modeling in context. Children and Youth Services Review, 79, 291-298. 
Dettlaff, A. J., Rivaux, S. L., Baumann, D. J., Fluke, J. D., Rycraft, J. R., \& James, J. (2011).

Disentangling substantiation: The influence of race, income, and risk on the substantiation decision in child welfare. Children and Youth Services Review, 33, 1630-1637.

Douglas, H., \& Walsh, T. (2010). Mothers, domestic violence, and child protection. Violence Against Women, 16, 489-508.

Dunlop, J. A. (2004). Judging Nicholson: An Assessment of Nicholson v. Scoppetta. Denver University Law Review, 82, 671-690.

Edleson, J. L. (1999). The overlap between child maltreatment and woman battering. Violence Against Women, 5, 134-154.

Edleson, J. (2004). Should childhood exposure to adult domestic violence be defined as child maltreatment under the law? In P. Jaffe, L. Baker, \& A. Cunningham (Eds.), Protecting children from domestic violence: Strategies for community intervention (pp. 8-29). New York: Guilford.

Edleson, J. L., Gassman-Pines, J., \& Hill, M. B. (2006). Defining child exposure to domestic violence as neglect: Minnesota's difficult experience. Social Work, 51, 167-174.

Edleson, J. L., Shin, N., \& Johnson Armendariz, K. K. (2008). Measuring children's exposure to domestic violence: The development and testing of the Child Exposure to Domestic Violence (CEDV) Scale. Children and Youth Services Review, 30, 502-521.

https://doi.org/10.1016/j.childyouth.2007.11.006

English, D. J., Edleson, J. L., \& Herrick, M. E. (2005). Domestic violence in one state's child protective caseload: A study of differential case dispositions and outcomes. Children and Youth Services Review, 27, 1183-1201. https://doi.org/10.1016/j.childyouth.2005.04.004 
Finkelhor, D., Turner, H. A., Shattuck, A., \& Hamby, S. L. (2015). Prevalence of childhood exposure to violence, crime, and abuse: Results from the National Survey of Children's Exposure to Violence. JAMA Pediatrics, 169, 746-754. https://doi.org/10.1001/jamapediatrics.2015.0676

Font, S. A., \& Maguire-Jack, K. (2015). Decision-making in child protective services: Influences at multiple levels of the social ecology. Child Abuse \& Neglect, 47, 70-82.

Henry, C. (2018). Exposure to domestic violence as abuse and neglect: Constructions of child maltreatment in daily practice. Child Abuse \& Neglect, 86, 79-88.

Henry, C. (2017). Expanding the legal framework for child protection: Recognition of and Response to child exposure to domestic violence in California law. Social Services Review, 91, 203-232.

Holt, S., Buckley, H., \& Whelan, S. (2008). The impact of exposure to domestic violence on children and young people: A review of the literature. Child Abuse \& Neglect, 32, 797-810.

Holden, G. W. (2003). Children exposed to domestic violence and child abuse: Terminology and taxonomy. Clinical Child and Family Psychology Review, 6, 151-160.

Kantor, G. K., \& Little, L. (2003). Defining the boundaries of child neglect: When does domestic violence equate with parental failure to protect? Journal of Interpersonal Violence, 18, 338-355.

Kernic, M. A., Wolf, M. E., Holt, V. L., McKnight, B., Huebner, C. E., \& Rivara, F. P. (2003). Behavioral problems among children whose mothers are abused by an intimate partner. Child Abuse \& Neglect, 27, 1231-1246.

Kohl, P. L., Edleson, J. L., English, D. J., \& Barth, R. P. (2005). Domestic violence and pathways into child welfare services: Findings from the National Survey of Child and Adolescent Well-Being. Children and Youth Services Review, 27, 1167-1182. 
Latzman, N. E., Vivolo-Kantor, A. M., Clinton-Sherrod, A. M., Casanueva, C., \& Carr, C. (2017).

Children's exposure to intimate partner violence: A systematic review of measurement strategies. Aggression and Violent Behavior, 37, 220-235.

Lee, S. J., Sobeck, J. L., Djelaj, V., \& Agius, E. (2013). When practice and policy collide: Child welfare workers' perceptions of investigation processes. Children and Youth Services Review, 35, 634641.

Lipsky, M. (1980). Street-level bureaucracy: Dilemmas of the individual in public services. New York: Russel Sage Foundation.

McDonald, R., Jouriles, E. N., Ramisetty-Mikler, S., Caetano, R., \& Green, C. E. (2006). Estimating the number of American children living in partner-violent families. Journal of Family Psychology: JFP: Journal of the Division of Family Psychology of the American Psychological Association (Division 43), 20, 137-142.

Naughton, C. M., O’Donnell, A. T., \& Muldoon, O. T. (2017). Exposure to domestic violence and abuse: Evidence of distinct physical and psychological dimensions. Journal of Interpersonal Violence. Advance online publication. doi: 10.1177/0886260517706763.

Nixon, K. L., Tutty, L. M., Weaver-Dunlop, G., \& Walsh, C. A. (2007). Do good intentions beget good policy? A review of child protection policies to address intimate partner violence. Children and Youth Services Review, 29, 1469-1486.

North Carolina Division of Social Services (2016). Chapter VIII: Child protective services, section 1409: Domestic violence. In Family services manual volume I: Children's services. Accessed at: https://www2.ncdhhs.gov/info/olm/manuals/dss/csm-60/man/cs1409.pdf

Moles, K. (2008). Bridging the divide between child welfare and domestic violence services: Deconstructing the change process. Children and Youth Services Review, 30, 674-688. 
Ogbonnaya, I. N., \& Pohle, C. (2013). Case outcomes of child welfare-involved families affected by domestic violence: A review of the literature. Children and Youth Services Review, 35, 14001407.

R Core Team (2017). R: A language and environment for statistical computing. Vienna, Austria. Retrieved from https://www.R-project.org/

Raudenbush, S.W., \& Bryk, A.S. (2002). Hierarchical linear models: Applications and data analysis methods. Thousand Oaks, CA: Sage Publications.

Rabe-Hesketh, S., \& Skrondal, A. (2012). Multilevel and longitudinal modeling using Stata (3rd ed.). College Station, TX: Stata Press.

StataCorp (2015). Stata Statistical Software: Release 14. College Station, TX: StataCorp LP.

Vermont Department for Children and Families (2017). Policy 51: Child safety interventions. In Family services policy manual. Accessed at: http://dcf.vermont.gov/sites/dcf/files/FSD/Policies/51.pdf

Victor, B. G., Grogan-Kaylor, A., Ryan, J. P., Perron, B. E., \& Gilbert, T. T. (2018). Domestic violence, parental substance misuse and the decision to substantiate child maltreatment. Child Abuse \& Neglect, 79, 31-41.

Williams, N. J., \& Glisson, C. (2014). Testing a theory of organizational culture, climate and youth outcomes in child welfare systems: A United States national study. Child Abuse \& Neglect, 38, $757-767$. 
Table 1. Summary statistics for substantiated referrals by presence of CEDV-related maltreatment

\begin{tabular}{|c|c|c|c|c|}
\hline \multirow[b]{2}{*}{ Variable } & \multirow[b]{2}{*}{$\begin{array}{c}\text { Overall } \\
(\mathrm{N}=23,704) \\
(\%)\end{array}$} & \multicolumn{2}{|c|}{ CEDV-related referral } & \multirow[b]{2}{*}{ Test statistic } \\
\hline & & $\begin{array}{c}\text { No } \\
(\mathrm{N}=19,252) \\
(\%)\end{array}$ & $\begin{array}{c}\text { Yes } \\
(\mathrm{N}=4,452) \\
(\%)\end{array}$ & \\
\hline Case formally opened & $30.8 \%$ & $32.4 \%$ & $23.8 \%$ & $\begin{array}{c}\chi^{2}(\mathrm{df}=1)=123.9^{*} \\
V=.07\end{array}$ \\
\hline Number of perpetrators mean (s.d.) & $1.3(0.5)$ & $1.2(0.4)$ & $1.5(0.5)$ & $\begin{array}{c}\mathrm{t}(\mathrm{df}=6,063)=-27.2^{*} \\
\boldsymbol{d}=\mathbf{. 5 0}\end{array}$ \\
\hline Age of youngest perpetrator mean (s.d.) & $32.4(10.1)$ & $33.0(10.3)$ & $30.1(8.9)$ & $\begin{array}{c}\mathrm{t}(\mathrm{df}=7,477)=18.8^{*} \\
\boldsymbol{d}=\mathbf{2 9}\end{array}$ \\
\hline
\end{tabular}

Referral included perpetrator(s) of the following gender(s):

Female only

Male only

Both female and male

Number of children mean (s.d.)

Age of youngest child mean (s.d.)

Referral included child(ren) of the following gender(s):

Female only

Male only

Both female and male

Investigation included a child of the following race:

American Indian
Asian/Pacific Islander
Black
Latino
Multi-racial
White
Multiple races

Types of substantiated maltreatment mean (s.d.)

Includes substantiated allegation of:

$\begin{array}{cccc}42.1 \% & 43.6 \% & 35.6 \% & \chi^{2}(\mathrm{df}=2)=399.8^{*} \\ 41.6 \% & 42.4 \% & 38.3 \% & \boldsymbol{V}=.13 \\ 16.2 \% & 14.0 \% & 26.1 \% & \end{array}$

$\begin{array}{cccc}39.7 \% & 46.0 \% & 12.7 \% & \chi^{2}(\mathrm{df}=2)=1828.8^{*} \\ 34.3 \% & 32.3 \% & 43.0 \% & \boldsymbol{V}=. \mathbf{2 8} \\ 26.0 \% & 21.7 \% & 44.3 \% & \\ 1.4(0.8) & 1.4(0.7) & 1.7(0.9) & \mathrm{t}(\mathrm{df}=5,889)=-20.7^{*}, \\ & & & \boldsymbol{d}=. \mathbf{3 9} \\ 6.2(5.4) & 6.7(5.5) & 4.2(4.4) & \mathrm{t}\left(\mathrm{df}=\begin{array}{c}7,926)=32.4^{*}, \\ \boldsymbol{d}=\mathbf{. 4 7}\end{array}\right.\end{array}$

$\begin{array}{cccc}0.4 \% & 0.4 \% & 0.3 \% & \chi^{2}(\mathrm{df}=6)=73.4^{*} \\ 0.8 \% & 0.8 \% & 0.7 \% & V=.06 \\ 23.8 \% & 24.2 \% & 22.3 \% & \\ 5.9 \% & 5.6 \% & 7.0 \% & \\ 6.4 \% & 6.2 \% & 7.5 \% & \\ 61.1 \% & 61.5 \% & 59.4 \% & \\ 1.7 \% & 1.4 \% & 2.8 \% & \\ 1.7(0.8) & 1.6(0.8) & 1.8(0.9) & \mathrm{t}(\mathrm{df}=6,506)=-14.1^{*}, \\ & & & \boldsymbol{d}=. \mathbf{2 4}\end{array}$

$15.0 \%$

$12.9 \%$

$24.2 \%$

$$
\begin{gathered}
\chi^{2}(\mathrm{df}=1)=356.6^{*} \\
V=.12
\end{gathered}
$$




\begin{tabular}{|c|c|c|c|c|}
\hline Improper supervision & $36.3 \%$ & $35.5 \%$ & $39.5 \%$ & $\begin{array}{c}\chi^{2}(\mathrm{df}=1)=24.1^{*} \\
V=.03\end{array}$ \\
\hline Other & $5.2 \%$ & $5.5 \%$ & $3.8 \%$ & $\begin{array}{c}\chi^{2}(\mathrm{df}=1)=20.2^{*} \\
V=.04\end{array}$ \\
\hline Physical abuse & $29.2 \%$ & $32.2 \%$ & $16.4 \%$ & $\begin{array}{c}\chi^{2}(\mathrm{df}=1)=432.9^{*} \\
V=.14\end{array}$ \\
\hline Physical neglect & $29.4 \%$ & $28.8 \%$ & $31.7 \%$ & $\begin{array}{c}\chi^{2}(\mathrm{df}=1)=14.9^{*} \\
V=.09\end{array}$ \\
\hline Sexual abuse & $5.4 \%$ & $6.5 \%$ & $0.4 \%$ & $\begin{array}{c}\chi^{2}(\mathrm{df}=1)=260.3^{*} \\
\boldsymbol{V}=\mathbf{. 1 0}\end{array}$ \\
\hline Substance abuse & $14.4 \%$ & $14.6 \%$ & $13.5 \%$ & $\chi^{2}(\mathrm{df}=1)=3.1$ \\
\hline Threatened harm & $32.4 \%$ & $27.5 \%$ & $53.8 \%$ & $\begin{array}{c}\chi^{2}(\mathrm{df}=1)=1138.7^{*} \\
V=.22\end{array}$ \\
\hline
\end{tabular}

$V=$ Cramer's $\mathrm{V} ; d=$ Cohen's $\mathrm{d}$

* Statistically significant at an alpha level of .05 
Table 2. Summary statistics for substantiated referrals involving CEDV-related maltreatment

\begin{tabular}{|c|c|c|c|}
\hline \multirow[b]{2}{*}{ Variable } & \multicolumn{2}{|c|}{ Case formally opened } & \multirow[b]{2}{*}{ Test statistic } \\
\hline & $\begin{array}{c}\text { No } \\
(\mathrm{N}=3,389) \\
(\%)\end{array}$ & $\begin{array}{c}\text { Yes } \\
(\mathrm{N}=1,061) \\
(\%)\end{array}$ & \\
\hline Number of perpetrators mean (s.d.) & $1.4(0.5)$ & $1.5(0.5)$ & $\begin{array}{c}\mathrm{t}(\mathrm{df}=1,718.1)=-4.8^{*} \\
\boldsymbol{d}=\mathbf{. 1 7}\end{array}$ \\
\hline Age of youngest perpetrator mean (s.d.) & $30.0(8.9)$ & $30.4(8.8)$ & $\mathrm{t}(\mathrm{df}=1,787)=-1.1$ \\
\hline \multicolumn{4}{|l|}{$\begin{array}{l}\text { Referral included perpetrator(s) of the } \\
\text { following gender: }\end{array}$} \\
\hline $\begin{array}{l}\text { Female only } \\
\text { Male only } \\
\text { Both female and male }\end{array}$ & $\begin{array}{l}12.5 \% \\
45.3 \% \\
42.3 \%\end{array}$ & $\begin{array}{l}13.7 \% \\
35.8 \% \\
50.5 \%\end{array}$ & $\begin{array}{c}\chi^{2}(\mathrm{df}=2)=29.8^{*} \\
V=.08\end{array}$ \\
\hline Number of children mean (s.d.) & $1.6(0.9)$ & $1.9(1.0)$ & $\begin{array}{c}\mathrm{t}(\mathrm{df}=1,556)=-8.2^{*} \\
\boldsymbol{d}=\mathbf{. 3 1}\end{array}$ \\
\hline Age of youngest child mean (s.d.) & $4.2(4.4)$ & $4.3(4.4)$ & $\mathrm{t}(\mathrm{df}=1,759)=-0.5$ \\
\hline \multicolumn{4}{|l|}{$\begin{array}{l}\text { Referral included child(ren) of the } \\
\text { following gender: }\end{array}$} \\
\hline $\begin{array}{l}\text { Female only } \\
\text { Male only } \\
\text { Both female and male }\end{array}$ & $\begin{array}{l}36.4 \% \\
39.3 \% \\
24.4 \%\end{array}$ & $\begin{array}{l}33.2 \% \\
35.1 \% \\
31.8 \%\end{array}$ & $\begin{array}{c}\chi^{2}(\mathrm{df}=2)=22.9^{*} \\
V=.07\end{array}$ \\
\hline \multicolumn{4}{|l|}{$\begin{array}{l}\text { Investigation included child(ren) of the } \\
\text { following race: }\end{array}$} \\
\hline $\begin{array}{l}\text { American Indian } \\
\text { Asian/Pacific Islander } \\
\text { Black } \\
\text { Latino } \\
\text { Multi-racial } \\
\text { White } \\
\text { Multiple races }\end{array}$ & $\begin{array}{c}0.2 \% \\
0.8 \% \\
23.9 \% \\
7.0 \% \\
7.3 \% \\
58.3 \% \\
2.5 \%\end{array}$ & $\begin{array}{c}0.8 \% \\
0.3 \% \\
17.1 \% \\
6.9 \% \\
8.0 \% \\
62.9 \% \\
4.0 \%\end{array}$ & $\begin{array}{c}\chi^{2}(\mathrm{df}=6)=36.8^{*} \\
V=.09\end{array}$ \\
\hline Types of substantiated maltreatment mean (s.d.) & $1.7(0.7)$ & $2.4(1.0)$ & $\begin{array}{c}\mathrm{t}(\mathrm{df}=1416)=-20.3^{*} \\
d=.85\end{array}$ \\
\hline \multicolumn{4}{|l|}{ Includes substantiated allegation of: } \\
\hline Failure to protect & $22.3 \%$ & $30.0 \%$ & $\begin{array}{c}\chi^{2}(\mathrm{df}=1)=25.5^{*} \\
V=.08\end{array}$ \\
\hline Improper supervision & $38.3 \%$ & $43.2 \%$ & $\begin{array}{c}\chi^{2}(\mathrm{df}=1)=7.8^{*} \\
V=.04\end{array}$ \\
\hline
\end{tabular}




\begin{tabular}{|c|c|c|c|}
\hline Other & $3.1 \%$ & $6.3 \%$ & $\begin{array}{c}\chi^{2}(\mathrm{df}=1)=22.2 * \\
V=.07\end{array}$ \\
\hline Physical abuse & $14.5 \%$ & $22.7 \%$ & $\begin{array}{c}\chi^{2}(\mathrm{df}=1)=39.5^{*} \\
V=.09\end{array}$ \\
\hline Physical neglect & $29.1 \%$ & $40.3 \%$ & $\begin{array}{c}\chi^{2}(\mathrm{df}=1)=46.9^{*} \\
V=\mathbf{. 1 0}\end{array}$ \\
\hline Sexual abuse & $0.0 \%$ & $1.8 \%$ & $\begin{array}{c}\text { Fisher's exact test, } \mathrm{p}<0.001 \\
\mathbf{\Phi = . 1 1}\end{array}$ \\
\hline Substance abuse & $9.1 \%$ & $27.8 \%$ & $\begin{array}{c}\chi^{2}(\mathrm{df}=1)=240.0^{*} \\
V=.23\end{array}$ \\
\hline Threatened harm & $50.8 \%$ & $63.3 \%$ & $\begin{array}{c}\chi^{2}(\mathrm{df}=1)=49.7^{*} \\
V=.11\end{array}$ \\
\hline
\end{tabular}

$V=$ Cramer's V; $d=$ Cohen's d

* Statistically significant at an alpha level of .05 
Table 3. Multilevel logistic regression model

\begin{tabular}{|c|c|c|}
\hline Variable & Adjusted Odds Ratio & $\begin{array}{l}95 \% \text { Confidence } \\
\text { interval }\end{array}$ \\
\hline Number of perpetrators & 0.81 & $0.42-1.55$ \\
\hline Age of youngest perpetrator & 0.99 & $0.98-1.01$ \\
\hline \multicolumn{3}{|c|}{$\begin{array}{l}\text { Referral included perpetrator(s) of the } \\
\text { following gender: }\end{array}$} \\
\hline Female only & Ref & - \\
\hline Male only & 0.80 & $0.61-1.06$ \\
\hline Both female and male & 1.11 & $0.56-2.20$ \\
\hline Number of children & 1.36 & $1.20-1.54$ \\
\hline Age of youngest child & 1.01 & $0.98-1.04$ \\
\hline \multicolumn{3}{|c|}{$\begin{array}{l}\text { Referral included child(ren) of the } \\
\text { following gender: }\end{array}$} \\
\hline Female only & Ref & - \\
\hline Male only & 0.95 & $0.77-1.16$ \\
\hline Both female and male & 0.91 & $0.69-1.19$ \\
\hline \multicolumn{3}{|c|}{$\begin{array}{l}\text { Investigation included child(ren) of the } \\
\text { following race: }\end{array}$} \\
\hline White & Ref & - \\
\hline American Indian & 2.44 & $0.97-12.20$ \\
\hline Asian/Pacific Islander & 0.27 & $0.07-1.07$ \\
\hline Black & 0.94 & $0.72-1.20$ \\
\hline Latino & 1.02 & $0.72-1.45$ \\
\hline Multi-racial & 1.26 & $0.91-1.76$ \\
\hline Multiple races & 1.08 & $0.66-1.77$ \\
\hline \multicolumn{3}{|c|}{ Includes substantiated allegation of: } \\
\hline Failure to protect & 2.82 & $2.21-3.58$ \\
\hline Improper supervision & 2.62 & $2.06-3.34$ \\
\hline Other & 4.21 & $2.73-6.50$ \\
\hline Physical abuse & 3.76 & $2.91-4.87$ \\
\hline Physical neglect & 4.25 & $3.30-5.47$ \\
\hline Substance abuse & 3.32 & $2.62-4.20$ \\
\hline Threatened harm & 1.83 & $1.51-2.20$ \\
\hline
\end{tabular}




\begin{tabular}{lccc}
\hline Level & $\begin{array}{c}\text { Intra-class correlation } \\
\text { coefficient }\end{array}$ & $\begin{array}{c}95 \% \text { confidence } \\
\text { interval }\end{array}$ & $\begin{array}{c}\text { Standard } \\
\text { error }\end{array}$ \\
\hline CPS worker & $26.1 \%$ & $19.5 \%-34.0 \%$ & .037 \\
CPS county office & $12.1 \%$ & $7.6 \%-18.7 \%$ & .028 \\
\hline
\end{tabular}

Note: Bolded values indicate an adjusted odds ratios that is significant at an alpha level of .05 based on an established confidence interval that does not include 0 .

Figure 1. Co-Substantiation of CEDV and other types of maltreatment

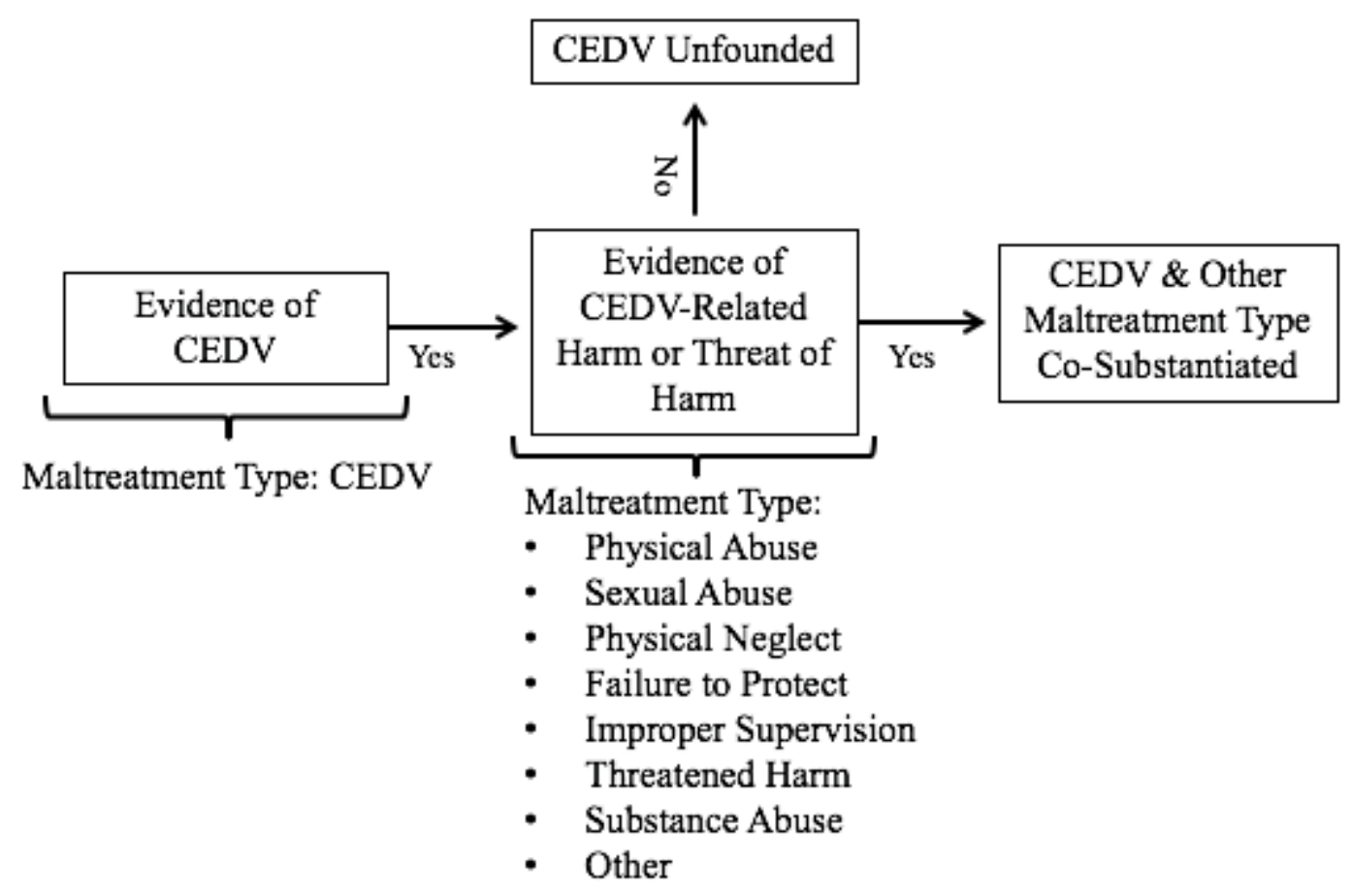


Figure 2. Predicted probability of a formal case opening for the 15 most prevalent patterns of CEDV-related maltreatment

\begin{tabular}{|c|c|c|}
\hline Pattern of maltreatment & Prevelance & robabilit \\
\hline Improper supervision; threatened harm & $13.9 \%$ & $21.8 \%$ \\
\hline Physical neglect; threatened harm & $11.3 \%$ & $29.4 \%$ \\
\hline Improper supervision & $11.1 \%$ & $14.4 \%$ \\
\hline Physical neglect & $10.3 \%$ & $20.2 \%$ \\
\hline Failure to protect & $7.6 \%$ & $15.1 \%$ \\
\hline Failure to protect; threatened harm & $5.1 \%$ & $22.9 \%$ \\
\hline Physical abuse; threatened harm & $5.1 \%$ & $27.3 \%$ \\
\hline Physical abuse & $3.6 \%$ & $18.6 \%$ \\
\hline Threatened harm & $2.8 \%$ & $10.9 \%$ \\
\hline Improper supervision; substance abuse; threatened harm & $2.4 \%$ & $42.5 \%$ \\
\hline Improper supervision; substance abuse & $2.0 \%$ & $31.3 \%$ \\
\hline Physical neglect; substance abuse & $1.3 \%$ & $40.3 \%$ \\
\hline Physical neglect; substance abuse; threatened harm & $1.3 \%$ & $52.1 \%$ \\
\hline Failure to protect; improper supervision & $1.2 \%$ & $28.5 \%$ \\
\hline Failure to protect; physical abuse & $1.2 \%$ & $34.9 \%$ \\
\hline
\end{tabular}

